ISSN: 0212-0267

DOI: http://dx.doi.org/ro.I420I/hedu20I635335360

\title{
LOS EDIFICIOS ESCOLARES EN UNA COMARCA LEONESA: METÁFORAS Y ESTUDIO DE CASO
}

\section{The school buildings in a region of Leon: metaphors and case study}

\author{
Isabel Cantón MaYo \\ Universidad de León \\ Correo-e: icanm@unileon.es \\ Cristina González García \\ Universidad de León
}

Correo-e:cgonzgos@estudiantes.unileon.es

Sheila Hidalgo GonzÁlez

Universidad de León

Correo-e: shidagoo@estudiantes.unileon.es

Recepción: Io de julio de 20I5. Envío a informantes: 20 de julio de 2015 .

Fecha de aceptación definitiva: 7 de mayo de 2016

Resumen: Introducción. El objetivo de este trabajo es hacer un estudio sobre los edificios escolares de una comarca leonesa llamada La Cepeda. Abarca desde la construcción de la primera escuela de la que tenemos documentos en la zona (1890) a la última construida en 1983. Método. La metodología empleada es mixta: etnográfica recogiendo datos de campo de los 46 edificios estudiados y también descriptivointerpretativa y hermenéutica, recogiendo datos de archivos de educación e históricos, amén de la bibliografía sobre la escuela en la época estudiada. Resultados. La hipótesis central del tema es que la evolución de las construcciones escolares en la comarca de La Cepeda tiene un paralelismo con el desarrollo económico y social de la misma. Se clasifican temporalmente y metafóricamente los edificios escolares estudiados en: a) Del inicio a 1920, que hemos llamado escuela pastoril; b) de 1920 a 1950, que hemos llamado escuela campesina, y c) de 1950 a 1983, que hemos llamado escuela monástica. En cada etapa se señalan los pueblos que tienen 
cada tipo de escuela, los materiales de construcción, el espacio del que disponían y las características del edificio. Discusión. Los resultados suponen una importante aportación al patrimonio arquitectónico escolar acosado por pérdidas y derribos de algunos edificios. El conocimiento de la importancia de las edificaciones escolares hoy reconvertidas en edificios de uso público o en bares y lugares de diversión.

Palabras Clave: construcciones escolares; escuelas leonesas; arquitectura escolar; metáforas de construcciones; elementos arquitectónicos.

Aвstract: Introduction. The aim of this essay is to study the school buildings in a region called La Cepeda, in León. It includes a variety of buildings from the construction of the first school in the area (1896) to the last one built in 1983. Method. The methodology deals with ethnography through which field data of forty-six buildings were collected, but also with descriptive-interpretative and hermeneutical methodology through which data about files of History and Education, in addition to the literature of schools in the period studied were compiled. Results. The main hypothesis of the issue copes with the fact that the evolution of school buildings in the region of the Cepeda has a parallelism with the economic and social development of it. These buildings are temporarily classified and they are also metaphorically studied in: a) from the start date of 1920 we have called pastoral school; b) from I920 to I950 which are called peasant school and c) from I950 to 1983 which we have called monastic school. In every period it is specified the villages which have every type of school, building materials, the space arrangement and the certain building characteristics. Discussion. The results are unprecedented and they also represent a significant contribution to the school's architectural heritage although there is a piece of missing information due to the fact that some buildings were demolished as well as losses. The knowledge of the importance of school buildings are converted into public buildings, in bars and other type of places.

KEY WORDS: school buildings; schools from Leon; school architecture; construction metaphors; architectural elements.

\section{Introducción}

$\mathrm{D}$ ecía Winston Churchill que si vivimos en una choza nos comportaremos como mendigos y que si vivimos en un palacio nos comportaremos como príncipes. Frente a la idea de que «la mejor Escuela es la sombra de un árbol» ${ }^{1}$ los regeneracionistas creían que la escuela debe ser «un lugar agradable, templado, limpio, con aire y luz», y a ello se pusieron nuestros antepasados decimonónicos, siendo León la provincia con más escuelas y maestros, edificando escuelas dignas con los máximos servicios para los niños de

Bello, L.: «Llegada a León. La provincia modelo», en BeLlo, L.: Viaje por las Escuelas de España, Madrid, Magisterio Español, 1926, pp. 204-208. Bello, L.: Viaje por las escuelas de Castilla y León, edición y estudio introductorio de Agustín Escolano, Ámbito, Valladolid, 1995. 
cada pueblo a cargo de un maestro vocacional, mal pagado, poco considerado y con dificultades de supervivencia. Torres Balbás ${ }^{2}$, arquitecto de la Oficina Técnica para la Construcción de Escuelas, siguiendo las enseñanzas de Giner³, señalaba que los pueblos se forman en torno a un caserío monumental que es la iglesia y que la gente vive en torno a ella en tugurios estrechos, ruinosos y sombríos y que disponen de una escuela en un local destartalado y sucio como una de tantas casas de vivienda. Ello hace que el aldeano atribuya valores diferentes a la escuela y a la iglesia. El espacio escolar es lugar de educación y socialización. Posee una dimensión educativa, como señala Mesmin ${ }^{4}$. Se pedía, por ello, una escuela de cal y canto para darle dignidad y aprecio por los asistentes y los habitantes. Se trata de conocer y apreciar lo que la escuela ofrece a los vecinos. Por ello: «El análisis de los espacios escolares exige, desde luego, atender a sus estructuras morfológicas materiales, pero también a su dimensión simbólica, a la función o actividad que en ellos se realiza y a las relaciones que existen entre los distintos espacios de una misma institución educativa»s.

Existe la idea de que la escuela ha estado siempre en los pueblos y ciudades españolas, pero debemos señalar con Lázaro ${ }^{6}$ que «el relato de nuestro crónico déficit de escuelas y de sus causas, déficit crónico que se arrastra hasta hoy mismo, aunque la perspectiva actual con que se contempla lo que parece sólo su residuo, sea, con mucho, la más esperanzadora de todas las que iremos bosquejando». El edificio escolar, tal y como hoy se concibe, tiene una extensión de poco más de un siglo y medio, adecuado a las necesidades docentes de la época. El modelo de enseñanza era pasivo y repetitivo acorde con la educación de la época.

Con la Ley Moyano ${ }^{7}$ se implantan definitivamente los grandes principios de la edad moderna: gratuidad (relativa) para la enseñanza primaria; sistema centralizado, uniformidad, secularización y libertad de enseñanza. Muestra la Ley una gran sensibilidad por los edificios para la Escuela Primaria: «En todo pueblo de 500 almas habrá necesariamente una Escuela pública elemental de niños, y otra, aunque sea incompleta, de niñas» (art. Ioo). En su artículo ro6 esta Ley recoge la importancia de la impartición de lecciones de noche o de domingo para los adultos, reconociendo la alta tasa de analfabetismo. Para abrir un centro de enseñanza primaria bastaba con tener veinte años cumplidos y poseer el título de Maestro. El control del Gobierno sobre la enseñanza se ejercía a través del Real Consejo de Instrucción Pública, presidido en la República por Miguel de Unamuno y más tarde por Lorenzo Luzuriaga. Un gran intento de llevar a cabo

Torres Balbás, L.: «Los edificios escolares vistos desde la España rural», en Exposición de arquitectura escolar, $\mathrm{I} 3,20$ y 27 de febrero de 1933.

3 Giner de los Ríos, B.: Las construcciones escolares de Madrid. Oficina Técnica para la construcción de escuelas, Madrid, Ministerio de Instrucción Pública y Bellas Artes, 1933.

4 Mesmin, G.: L'enfant, l'architecture et l'espace, Tournai, Casterman, 1973.

s Viñao, A.: «Escolarización, edificios y espacios escolares», CEE Participación Educativa (marzo, 2008), pp. I6-27.

6 Lázaro Flores, E.: «Historia de las construcciones escolares en España», Revista de Educación, n. ${ }^{\circ} 240$ (1975), pp. II4-I26.

Ley de Instrucción Pública de 9 de septiembre de 1857 (Ley Moyano 1857). 
un magno programa de construcciones escolares en la enseñanza primaria se realiza durante el sexenio de i868-1874, con bastante retraso respecto de otros países europeos como Francia o Bélgica.

Pero los deseos de papel tardaron en hacerse realidad en los pueblos. Además, cuando era posible tener una escuela ésta era de un nivel paupérrimo: «Solo para explicar la pobreza de estas escuelitas rurales y para admirar el buen deseo de los pueblos que, a pesar de todo, entre cuatro paredes de barro y un techo de paja sin salida de humos dan la cifra más honrosa de las estadísticas escolares» ${ }^{8}$. Sin embargo, son los pueblos quienes más empeño tienen en poseer su escuela y su maestro. En las ciudades había medios de trabajo y distracción de los que los pueblos carecían, por lo que su empeño en edificar, dotar y poseer una escuela era mayor: «La aldea conquista el primer puesto de la instrucción primaria en España. La ciudad, en cambio, se descuida»?. El empeño de los pueblos en poseer su propia escuela se constata por la venta de terrenos para obtener fondos para construirla, para dotarla o para reformarla de forma que fuera digna. Y es que «el edificio escolar, sus diversos espacios, los muros, las paredes, ventanas, puertas y muebles, junto con los rincones exteriores, jardines y espacios abiertos» son «elementos activos que conforman la experiencia de la escuela y la comprensión de la educación $»^{10}$.

Los datos iniciales de Escuelas públicas de primeras letras en León datan del Plan de Escuelas de la Diputación Provincial de I82I que señalaba que en todos los pueblos, fuera cual fuera el número de vecinos, habría una escuela de primeras letras. Fue efectivo, pues según recoge Madoz ${ }^{\mathrm{II}}$, hacia 1847 ya hay en la provincia 807 escuelas, y en 1928 se incrementan hasta las I.067 escuelas; en 1935 suben hasta I.83I escuelas y en I950 llegan a 2.405. Desde la República hay nuevamente un gran impulso en la construcción de edificios escolares y la dotación de servicios de apoyo y paralelos. Con la bajada de la población escolar rural, a partir de los años 1970 se ensayan dos modelos de escolarización rural opuestos: las concentraciones escolares, que agrupaban a los niños de los pueblos en una Escuela Graduada completa en una localidad mayor mediante el transporte, y, por otra parte, la creación de los Centros Rurales Agrupados (CRA), modelo inverso que intenta mantener a los niños en los pueblos y son los maestros especialistas los que se mueven ${ }^{12}$. Con todo no podemos menos que señalar el declive de las escuelas rurales leonesas y su falta de atención en el aspecto patrimonial. En el curso 20I3-I4, según recoge el Ministerio de Educación, hay en toda España io.317

8 Escolano Benito, A.: «Introducción», en Escolano Benito, A. y cols.: Historia ilustrada de la escuela de España: Dos siglos de perspectiva histórica, Madrid, Fundación Germán Sánchez Ruipérez, 2006, pp. I3-I4.

, Ibidem.

10 Burke, C.: «Introduction. Containing the school child: architectures and pedagogies», Paedagogica Historica, 4I (4-5), (2005), pp. 489-494.

" Madoz, P.: Diccionario geográfico-estadístico-historico de España y sus posesiones de ultramar, I886-1870/Junta de Castilla y León. Facsímil en 2012-I3.

${ }_{12}$ Corchón, E.: La escuela en el medio rural: modelos organizativos, Barcelona, Davinci Continental, 2005. 
centros de Educación Primaria públicos y en la provincia de León I32 CRA que, entendiendo que agrupan a varias de las antiguas escuelas unitarias, suponen multiplicar por siete su número. Esta política, aunque manteniendo las escuelas en los pueblos para frenar su despoblación, no ha sido capaz de contenerla. Ello hace que pueblos que en su día tuvieron cuatro o seis aulas hoy tienen clausuradas sus escuelas por falta de alumnos. Por eso, el abandono de los edificios escolares es constante y la pérdida patrimonial de los mismos importante. Sería deseable algún tipo de normativa que los protegiese, que pusiera en valor y que permitiese catalogar y estudiar estos centros como modelos escolares, arquitectónicos, etnográficos, culturales y patrimoniales. No dejemos perder las escuelas ya que constituyen una parte importante del patrimonio cultural de un pueblo; según la UNESCO, comprende las obras de sus artistas, arquitectos, músicos, escritores y sabios, así como las creaciones anónimas surgidas del alma popular, y el conjunto de valores que dan sentido a la vida, es decir, las obras materiales y no materiales que expresan la creatividad de ese pueblo, la lengua, los ritos, las creencias, los lugares y monumentos históricos, la literatura, las obras de arte y los archivos y bibliotecas ${ }^{13}$.

Este trabajo es una investigación sobre la arquitectura escolar en la comarca leonesa de La Cepeda. Esta zona está situada cercana a Astorga, pero posee características económicas, sociales y culturales propias. El hecho de que sólo unos pocos edificios escolares de la zona estudiada sigan abiertos y en uso, y otros se hallen hoy dedicados a clubs sociales o consultorios médicos muy modificados, nos ha hecho centrar en ellos la atención con el fin de inventariarlos y de preservar el patrimonio escolar.

\section{El contexto estudiado: La Cepeda y sus escuelas}

La Cepeda es una comarca perteneciente a la provincia de León. Es zona bastante bien delimitada y de transición entre las ubicadas en la meseta y la ribera leonesa y las que se hallan en la montaña. Se encuentra situada en dirección nortesur entre las comarcas de la Maragatería y de la Omaña, y en dirección este-oeste entre las del Órbigo Alto y de Boeza. Está constituida por cinco ayuntamientos: Magaz de Cepeda, Quintana del Castillo, Villagatón, Villamejil y Villaobispo de Otero. En total cuenta con cuarenta y cuatro núcleos de población, distribuidos en una extensión de 506,4 $\mathrm{km}^{2}$. Los municipios que forman Magaz de Cepeda (6), Villamejil (7) y Villaobispo de Otero (6) forman la llamada Cepeda Baja, mientras que los que encontramos en Quintana del Castillo (13) y Villagatón (I2) forman la denominada Cepeda Alta.

El clima de La Cepeda es de tipo continental, con inviernos fríos y veranos cálidos. La parte noroccidental está constituida por pizarras; mientras que el extremo

${ }_{13}$ Definición elaborada por la Conferencia Mundial de la unEsco sobre el Patrimonio Cultural, celebrada en México en el año I982. 
nororiental y el suroccidental son terrenos de cuarcita. En ella, los suelos pobres son los que más abundan, así lo aseguró ya Madoz cuando calificó los suelos de esta comarca de mediana, baja y, en algunos casos, de ínfima calidad ${ }^{14}$. Entre la vegetación natural destacan el roble y la encina, aunque como es propio de la zona, en las vegas, abundan el chopo, el aliso, el omero y las urces. Ello tiene inmediata repercusión en la construcción de los edificios escolares, son robustos para el frío y utilizan los materiales del suelo próximo en su alzado.
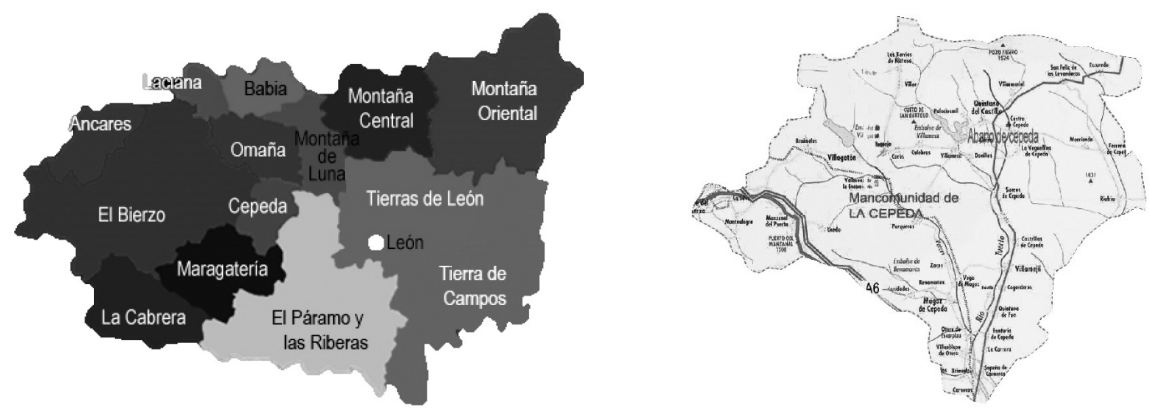

Fig. I. Mapa de las comarcas de León y de La Cepeda objeto de este estudio.

Los núcleos poblacionales están organizados conformes al modelo llamado de poblamiento rural concentrado. En esta comarca, encontramos numerosos castros, muestra de que en ella existieron pueblos prerromanos. La principal actividad económica de la comarca ha sido y es la agricultura, como corresponde a una zona eminentemente rural. Sin embargo, a lo largo de la historia han existido diferencias entre unos municipios y otros en cuanto a la superficie labrada, también, por tanto, en las ganancias obtenidas. La estructura productiva de $\mathrm{La}$ Cepeda se caracteriza por la existencia de explotaciones de pequeño tamaño, muy parceladas. Los núcleos urbanos son pequeños en general y ello se ha reflejado en la multitud de edificios escolares. No han existido en La Cepeda grandes fortunas que implementen la construcción de escuelas de indianos como ha ocurrido en Asturias, en la montaña leonesa, o en El Bierzo, si exceptuamos en La Cepeda la escuela de Villameca de la Fundación Sierra-Pambley's.

\section{Objetivos}

Los objetivos de esta investigación se enmarcan en una dimensión etnográfica y de tipo de inventario para evitar la pérdida del patrimonio arquitectónico escolar.

14 García Álvarez, A.: La Cepeda a finales del siglo XX, 2009, en http://www.saber.es/web/ biblioteca/libros/tierras-de-leon/html/65/2cepeda.pdf. Madoz, P.: Diccionario Geográfico-Estadístico-Histórico de España y sus posesiones de Ultramar, 1845-50, Edición Facsímil, I983. Tomo de León, Valladolid: Ediciones Ámbito.

is Cantón Mayo, I.: 1996, ibidem. 
I. Clasificar temporalmente los edificios escolares de la comarca leonesa de La Cepeda en función de su antigüedad y cambios sucesivos.

2. Inventariar las escuelas cepedanas para evitar su pérdida de identidad y conocer su devenir espacio-temporal.

3. Identificar elementos arquitectónicos comunes en las escuelas de la zona señalada como adaptación de la arquitectura escolar a la arquitectura rural del contexto donde se enmarcan.

\section{Metodología}

La metodología ha sido mixta: a) etnográfica, con estudio de campo recogiendo de los distintos pueblos datos y fotografías de los edificios escolares existentes; b) descriptiva, estudiando cada edificio, inventariándolo y señalando sus características propias; y c) hermeneútica, ya que nos ofrece una interpretación personal y otra consideración distinta con respecto a la realidad de las significaciones latentes; se trata de la hermeneia griega, que significa el acto de la interpretación. El número de edificios escolares estudiados abarca los cinco Ayuntamientos de La Cepeda y comprende 46 pueblos y más de 60 edificios escolares: Ayuntamiento de Quintana del Castillo: I4 pueblos; Ayuntamiento de Magaz de Cepeda: 6 pueblos; Ayuntamiento de Villamejil: 6 pueblos; Ayuntamiento de Villagatón: I3 pueblos; Ayuntamiento de Villaobispo: 6 pueblos. Teniendo en cuenta que varios de los pueblos tenían más de una escuela. En segundo lugar se ha hecho una revisión del contenido de las 46 escuelas en el Archivo Histórico Provincial de León, en la Dirección Provincial de Educación y en la Unidad de Construcciones Escolares de la Provincia de León. En este caso el método ha sido descriptivointerpretativo. Se recogían los datos de planos, edificios, estado de conservación, etc., y se catalogaban los datos obtenidos en función de la época de la edificación y de las características arquitectónicas espaciales: aulas, aseos, vestíbulos, calefacción, casas de maestros, etc.

Un estudio puede realizarse de diversas formas, reproductiva, explicativa o normativa, para comprender e interpretar los hechos. Se ha trabajado con la interpretación al clasificar los edificios escolares investigados ${ }^{16}$. Por otra parte, la investigación etnográfica permite un proceso de construcción teórica simultánea a la investigación empírica ${ }^{17}$ y ello nos ha inducido al trabajo realizado sobre los edificios escolares. A ello se une una larga tradición metafórica en educación que permite representar o describir algo por semejanza o por analogía. Hablar de la escuela metafóricamente supone aplicarle diferentes semejanzas como ha hecho Morgan ${ }^{18}$ en su libro Imágenes de la organización, que utiliza la metáfora para ver y comprender a las organizaciones de un modo distinto. Por ejemplo,

i6 Schokel, L. y Bravo, J. M.: Apuntes de hermenéutica, Madrid, Editorial Trotta, 1994.

${ }^{17}$ Jackson, Philip W.: La vida en las aulas, Madrid, Morata (2. ${ }^{a}$ ed.), 1992.

18 Morgan, G.: Images of organization, Sage, USA, $2^{\text {nd }}$ Edition, traducción española, Madrid, Alhambra, 1997. 
él presenta las siguientes metáforas sobre la organización: máquina, organismo, cerebro, cultura, sistemas políticos, cárceles psíquicas, cambio y transformación e instrumentos de dominación. Todas ellas han sido desarrolladas aplicadas al centro escolar al que se han añadido: escuela cuartel, caja negra, arenas movedizas, etc. En este trabajo desarrollamos tres metáforas para interpretar y describir los edificios escolares de La Cepeda en la provincia de León: escuelas pastoriles, escuelas campesinas y escuelas monásticas, en una especie de devenir diacrónico con sus características propias.

\section{Resultados}

\section{I. Escuelas construidas entre I890 y 1920. Escuelas pastoriles}

La denominación de escuelas pastoriles obedece a la construcción de escuelas primitivas y simples. Son muchas las autonomías que han recuperado las antiguas chozas pastoriles como elementos etnográficos importantes. Destacan en esta línea Aragón, Asturias y el País Vasco, que han recuperado las cabañas de los pastores como parte de su patrimonio. En esta línea hemos hecho a la vez una metáfora, por lo similares, y una analogía, por lo simples, para esta denominación que hemos atribuido a los primeros edificios escolares encontrados en la comarca cepedana.

Desde la Ley Moyano'19 (1857) se inicia la preocupación por el espacio escolar y por establecer una previsión de una asignación anual de un millón de reales para auxiliar a los pueblos que no podían costear por sí solos los gastos de la primera enseñanza, ya que, en aquel momento, la construcción de escuelas recaía en los Ayuntamientos $^{20}$. Por ello, las primeras escuelas públicas construidas hasta 1920 dependen de los Ayuntamientos. A partir de esa fecha pasan al Estado, pero los Ayuntamientos también tienen que colaborar en su mantenimiento. La Instrucción Técnico-Higiénica relativa a la construcción de escuelas de 28 de abril de I905 regulaba por primera vez en España, a título orientativo, todo lo relativo a su emplazamiento, orientación, extensión, construcción, ventilación, iluminación y calefacción, así como los locales o dependencias, los requisitos técnico-higiénicos que debían reunir las aulas y las características del mobiliario ${ }^{21}$.

Había gran escasez de escuelas como lo prueba el hecho de que el número de habitantes por unidad escolar en León es de 340,17 y la media de escuelas por pueblo es de 0,6I y contando los Ayuntamientos es de 4,48. Llama la atención que sólo 92 de las 715 escuelas de la provincia de León estén en edificios propios y que en Astorga, zona colindante y cabeza de la comarca de La Cepeda, por ejemplo, de

19 Ley de Instrucción Pública de 9 de septiembre de 1857 (Ley Moyano I857).

20 FERnÁndez GutiéRrez, M. F.: «El contexto del proyecto arquitectónico: la renovación de la construcción escolar en España (1920-1936)», Boletín de Letras del Real Instituto de Estudios Asturianos (BIDEA), Oviedo, n. ${ }^{\circ}$ I57 (enero-junio, 200I), pp. 177-245.

${ }^{21}$ VIÑAO, A.: «Escolarización, edificios y espacios escolares», CEE Participación Educativa (marzo, 2008), pp. 16-27. 
8I escuelas, 7I son de niños y de temporada, una es de niñas y 6 de niños completas. Desde la Ley Moyano el incremento de escuelas es espectacular, pues en i867 se alcanza en León la cifra de i.309 escuelas primarias. Ello representa una proporción de 275,I2 habitantes por escuela. En 1900 Mingote $^{22}$ señala que existen en la provincia I.3I2 escuelas y en 1903 ya hay I.503 escuelas en León provincia. Hasta I900 no se prohíbe el trabajo infantil, pero en el campo este hecho no se tuvo en cuenta hasta bien avanzada la segunda mitad del siglo, por lo que pocos niños completaban los ciclos escolares. La tasa de analfabetismo en León en i9ıo era del 47,29\% y en 1930 ya bajó al 37\%. Los datos de Samaniego ${ }^{23}$ ilustran la situación leonesa:

\begin{tabular}{|c|c|c|c|c|c|c|}
\hline \multicolumn{6}{|c|}{ Situación escolar en León en I928-I930 (Samaniego, I977) } \\
\hline $\begin{array}{c}\text { Población } \\
\text { de derecho }\end{array}$ & $\begin{array}{c}\text { Población escolar } \\
\text { en escuelas } \\
\text { nacionales }\end{array}$ & $\begin{array}{c}\text { Número } \\
\text { de escuelas }\end{array}$ & $\begin{array}{c}\text { Núm. de } \\
\text { maestros }\end{array}$ & $\begin{array}{c}\text { Escuelas } \\
\text { x I.000 } \\
\text { habitantes }\end{array}$ & $\begin{array}{c}\text { Promedio de } \\
\text { niños de ambos } \\
\text { sexos }\end{array}$ & $\begin{array}{c}\text { Maestros } \\
\text { x I.000 } \\
\text { habitantes }\end{array}$ \\
\hline 436.369 & 89.759 & I.067 & I.548 & 3,48 & 59,52 & 3,54 \\
\hline
\end{tabular}

El año 1920 marcó el fin del monopolio municipal y de la paralela abstención estatal en cuanto a construcción de escuelas. Con el Decreto de 23 de noviembre de 1920 se reconoció, por primera vez y oficialmente, la mala situación de los locales escolares. Asimismo, el mencionado decreto estableció un sistema de colaboración entre el Estado y los municipios para construir escuelas. Las escuelas eran unitarias con todas las especificidades de este tipo de escuelas ${ }^{24}$.

Entre los edificios escolares de la comarca de La Cepeda se ha encontrado que los edificios escolares más antiguos fueron edificados entre I890 y 1920, es decir, fueron a cargo de los pueblos y Ayuntamientos. La más arcaica data del año i89o, nos referimos a la escuela de La Silva.

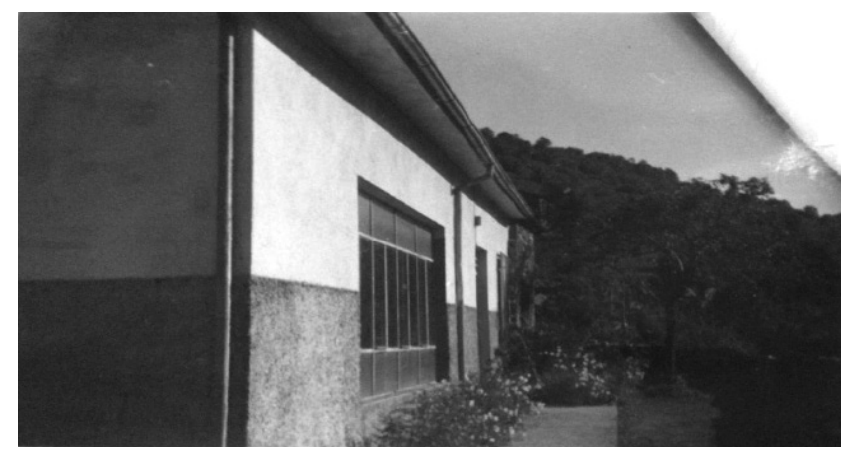

Ilustración i. Escuela de La Silva. Año de construcción i89o.

Archivo Histórico Provincial de León.

22 Mingote y Tarazona, P.: Guía del viajero en León y su provincia, León, Establecimiento Tipográfico de Miñón, I879.

${ }_{23}$ Samaniego Boneu, M.: La política educativa de la segunda República durante el bienio Azañista, Madrid, csic, 1977.

24 Jiménez SÁnchez, J.: La escuela unitaria, Barcelona, Laia, 1983. 
Otros ejemplos de escuelas edificadas entre finales del siglo XIX y principios del siglo xx son las correspondientes a los pueblos de Montealegre, Manzanal del Puerto, Brimeda, Carneros, Castro, Vanidodes, Requejo, Escuredo y Palaciosmil. Todas ellas fueron levantadas antes de finalizar la segunda década de r9o0.

Como se puede observar en las imágenes siguientes, en estas construcciones existían ciertas similitudes, y también diferencias notorias en los elementos empleados para su edificación. Las diferencias responden a la zona donde se encuentran ubicadas, pues aunque los pueblos citados pertenecen a la misma comarca leonesa, unos corresponden a la denominada Cepeda baja y otros a La Cepeda alta. Así, en La Cepeda baja los edificios escolares fueron construidos con teja y tapial (Carneros, Brimeda) y, por el contrario, en La Cepeda alta fueron levantadas con pizarra y piedra (Palaciosmil o Manzanal del Puerto). Ello se debe a la abundancia en un tipo u otro de material más próximo: la zona alta, dentro de los Montes de León, tiene abundancia de piedra y pizarra, que son también los materiales con las que se construyen las viviendas particulares; la zona baja, por el contrario, es rica en barro y tierra que permite con menos coste y trabajo la construcción con tapial y teja, que, aunque menos resistente, es más fácil y rápida en erigirse.

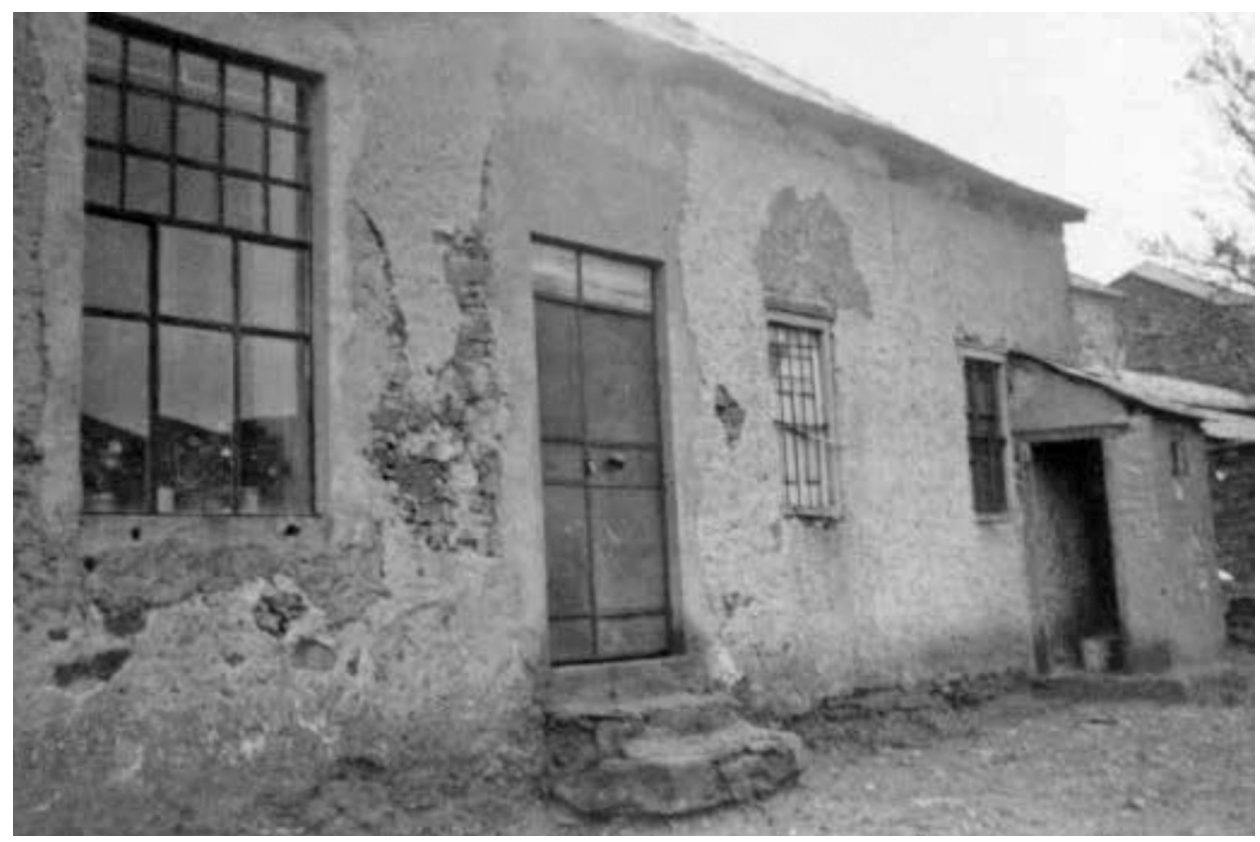

Ilustración 2. Escuela de Montealegre. Año de construcción i896.

Archivo Histórico Provincial de León.

La distribución de las dependencias era en todas las escuelas muy parecida. Contaban con un espacio destinado a un aula unitaria, podía o no haber un aseo y un espacio destinado a vivienda para el maestro. Así, encontramos que el plano 
LOS EDIFICIOS ESCOLARES EN UNA COMARCA LEONESA:

METÁFORAS Y ESTUDIO DE CASO

ISABEL CANTÓN, CRISTINA GONZÁLEZ Y SHEILA HIDALGO

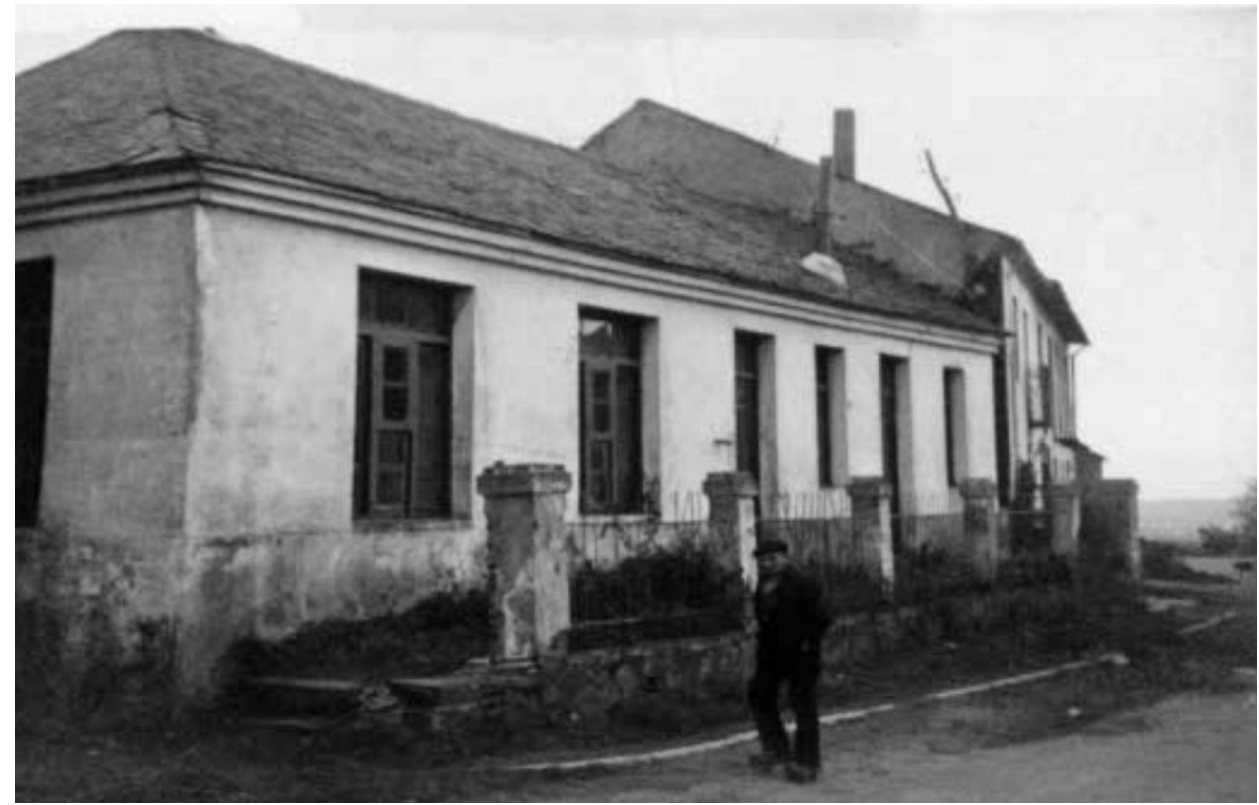

Ilustración 3. Escuela de Manzanal del Puerto. Año de construcción igoo. Archivo Histórico Provincial de León.

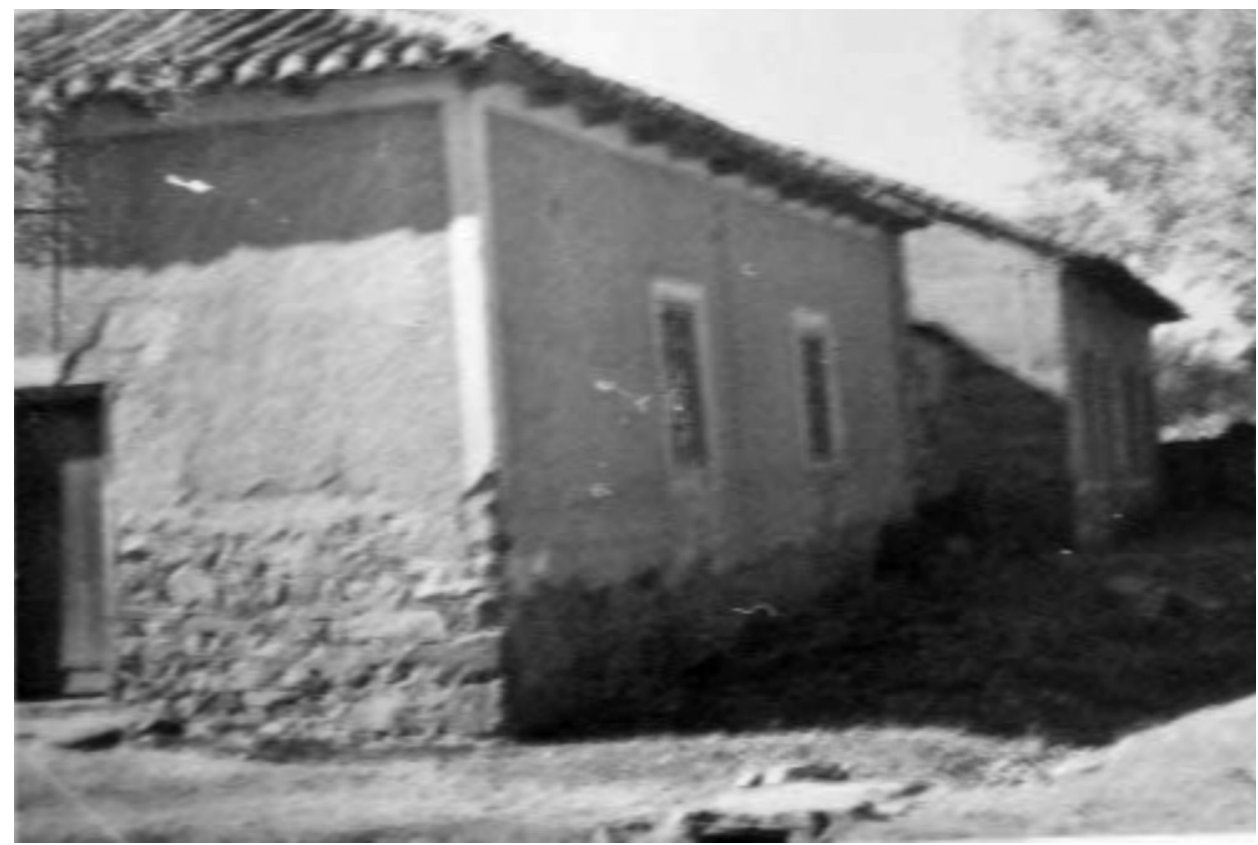

Ilustración 4. Escuela de Brimeda. Año de construcción igoo.

Archivo Histórico Provincial de León. 


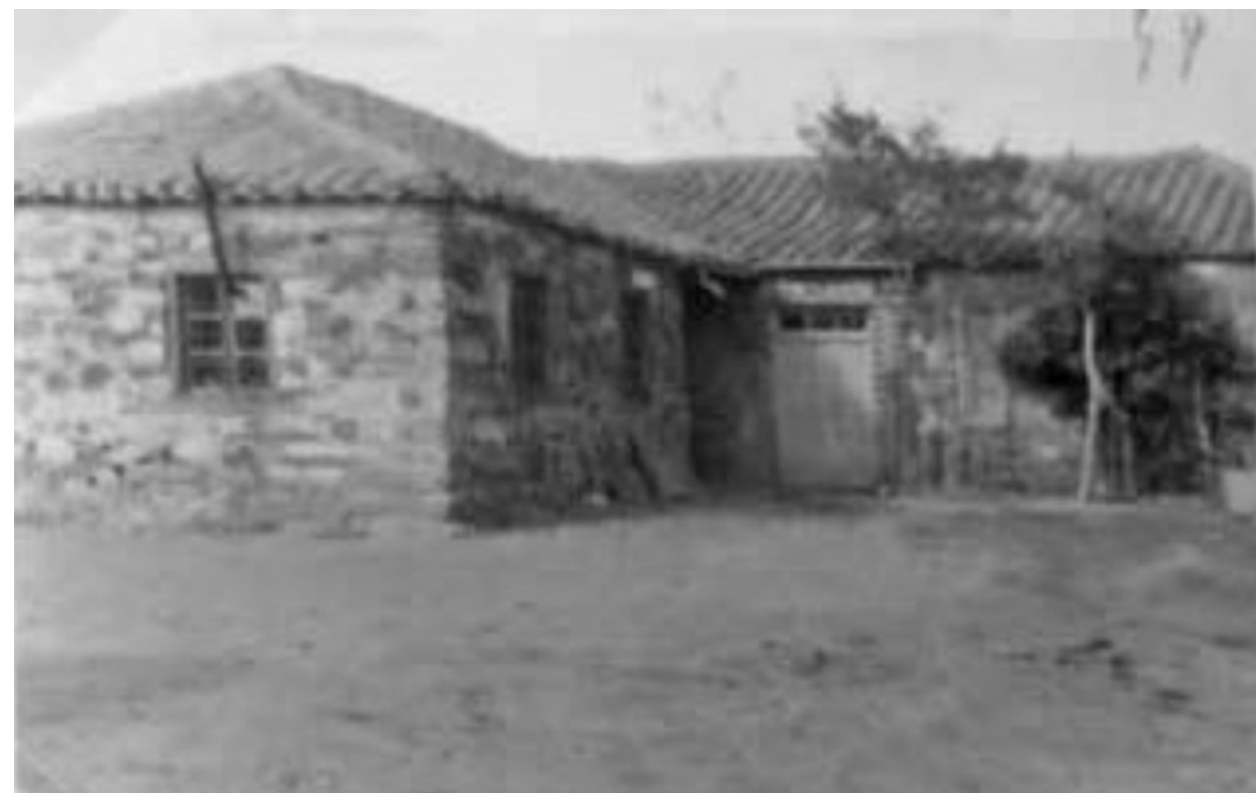

Ilustración 5. Escuela de Castro. Año de construcción i908.

Archivo Histórico Provincial de León.

del interior era muy similar al que aquí se recoge, que corresponde a la escuela de La Silva (1890). Es la arquitectura escolar más primitiva y funcionalista que corresponde a las necesidades básicas de la escuela rural de un maestro un aula. Las escuelas más primitivas estudiadas tienen pocas ventanas para evitar el frío, muros en piedra o tapial, techados en paja en un primer momento y luego en pizarra. La calefacción se procuraba mediante estufas de leña que el propio maestro encendía, aunque los vecinos le procuraban la leña. Teniendo en cuenta la interpretación utilizada éste es un modelo que hemos llamado escuela corral o cabaña, por su similitud con las edificaciones que albergaban ganado.

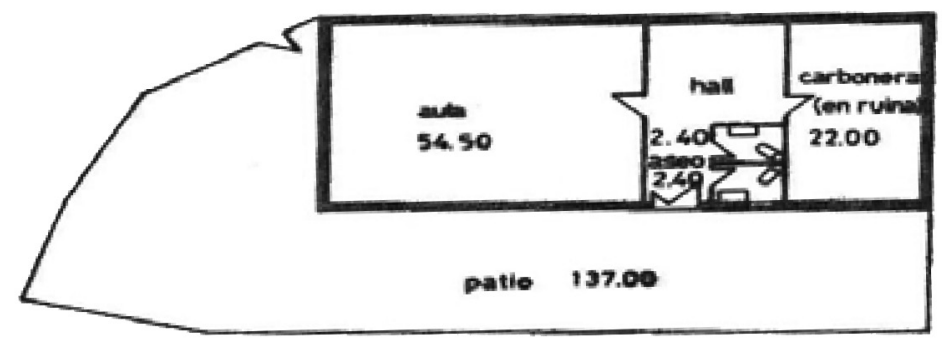

CIRCULACIONES $=1627 \mathrm{M}^{2}$

Ilustración 6. Plano del interior de la escuela de La Silva. Año 1986. Dirección Provincial de Educación de León. 
LOS EDIFICIOS ESCOLARES EN UNA COMARCA LEONESA:

METÁFORAS Y ESTUDIO DE CASO

ISABEL CANTÓN, CRISTINA GONZÁLEZ Y SHEILA HIDALGO

\subsection{Escuelas construidas desde I920 hasta 1950. Escuelas campesinas}

Siguiendo con las metáforas escolares citadas de Morgan², y el estudio de las escuelas cepedanas, encontramos que las casas campesinas españolas tienen diferentes denominaciones según la región en la que se encuentren: la masía catalana, el pazo gallego, la barraca valenciana, el caserío vasco, el carmen granadino, el cigarral toledano, los hórreos asturianos y gallegos, el cortijo andaluz o la venta manchega, etc. En el Bierzo leonés, cercano a La Cepeda, tenemos como construcción típica la palloza, amén de muchos otros tipos que definen la geografía española. En la comarca cepedana el tipo de construcción era una casa básica de vivienda, primero de planta baja, más tarde de planta y piso con un corral y una parte atrás dedicada a los animales. Esta estructura se reproduce en los edificios escolares construidos de forma casi masiva en la República y algo en la posguerra, ya que los maestros tenían fuerte implantación en la localidad en la que desempeñaban su escuela.

Fue este un periodo en el que la tarea de construir escuelas recibió un impulso por parte de los sucesivos gobiernos. En un primer momento la edificación de escuelas aumentó sensiblemente en relación con cualquier época anterior. En 1928 el Decreto de ro de julio creaba las Comisiones Provinciales, antecedentes de las Juntas Provinciales, a través de las cuales los Ayuntamientos debían solicitar la construcción de los edificios escolares. Asimismo, en este periodo se desarrolló el primer Plan Quinquenal de Construcciones Escolares ${ }^{26}$, mediante el cual se propuso construir todas las escuelas que faltaban.

Además, en 1945 con la promulgación de la Ley de Educación Primaria el Estado estimuló la creación de escuelas, aunque su intervención sería meramente subsidiaria, por lo que de nuevo la responsabilidad de construir los edificios escolares recaía en los municipios.

El inspector Medina $\mathrm{Bravo}^{27}$ considera la situación de la enseñanza en León gratamente satisfactoria teniendo en cuenta que la creación de escuelas se hace a petición de los pueblos y siempre que los Ayuntamientos faciliten local en condiciones y material necesario para que comience a funcionar. Considera que la provincia de León tiene el mayor número de escuelas porque existe una gran preocupación por la enseñanza y la escuela. Idéntico parecer al de Luis Bello (1926). En I930 ya hay I.607 escuelas en funcionamiento, pero aún hay puntos negros en la provincia y se citan La Cabrera, Ancares y La Cepeda (objeto de este estudio). El informe de Educación de ese año proponía la necesidad de demostrar la atención del Estado y que sean visitadas todas las Escuelas nacionales de la Cabrera, Fornela, Ancares y en La Cepeda. En 1935 hay en León I83r escuelas y además ahora está prácticamente equilibrado el número de escuelas de niños y niñas, el resto son mixtas. El progreso se nota ya que en 1950 en que hay 2.405 escuelas en la provincia de León,

25 Morgan: ibidem.

26 Carreras, A. y Tafunell, X.: Estadísticas históricas de España, Madrid, fundación BbVA, 2005.

${ }^{27}$ Hernández, J. M.: La Escuela Primaria en Castilla y León: Estudios Históricos, Valladolid, Ámbito, 1993. 
con una buena proporción por sexos y más de la mitad mixtas. Este incremento se debe a la labor de arquitectos como Manuel de Cárdenas, Sáinz de Esquerra, Amós Salvador o Nicasio Guisasola, y a inspectores como Modesto Medina Bravo o Rafael Álvarez. Alta tasa de nacimientos pero también de mortalidad infantil con enfermedades infecciosas, sarampión, escarlatina, viruela, difteria, tifus, tosferina, pulmonía, y otras como catarros, gripes, diarreas, cólicos, quistes, triquinosis, etc., debidas a la falta de higiene y a la masificación de niños en las escuelas (llegaban a Ioo en algunos casos) hacía que la población se viera diezmada. Alonso y Garrote ${ }^{28}$ se refiere en concreto a las situadas en la comarca de Astorga. Hubo hasta catecismos del Gobierno e iniciativas particulares en el mismo sentido ${ }^{29}$ para la higiene escolar a fin de evitar este nivel de mortandad infantil.

Entre las escuelas alzadas en este periodo en la citada comarca leonesa encontramos que superan en número a las levantadas en el periodo anterior, así, según datos oficiales existentes hoy día, se habrían construido veintidós escuelas, frente a las once edificadas entre finales del siglo xix y principios del xx. En la década de los años veinte, fueron construidas dos escuelas, la de Quintana del Castillo y la de Villameca. Así, en las dos décadas siguientes la cantidad de edificaciones escolares se incrementó. En los años treinta fueron construidas las escuelas de Tabladas, Villar, Corús, Culebros, Villaobispo de Otero, Benamarías, Magaz de Cepeda, Vega de Magaz, Zacos, Morriondo y San Feliz de las Lavanderas. Haciendo un total de once escuelas. En los años cuarenta fueron edificadas las de Ucedo, Valbuena de la Encomienda, Villagatón, Castrillos de Cepeda, Revilla, Sueros de Cepeda, Sopeña, Abano y Riofrio. Sumando un total de nueve escuelas.

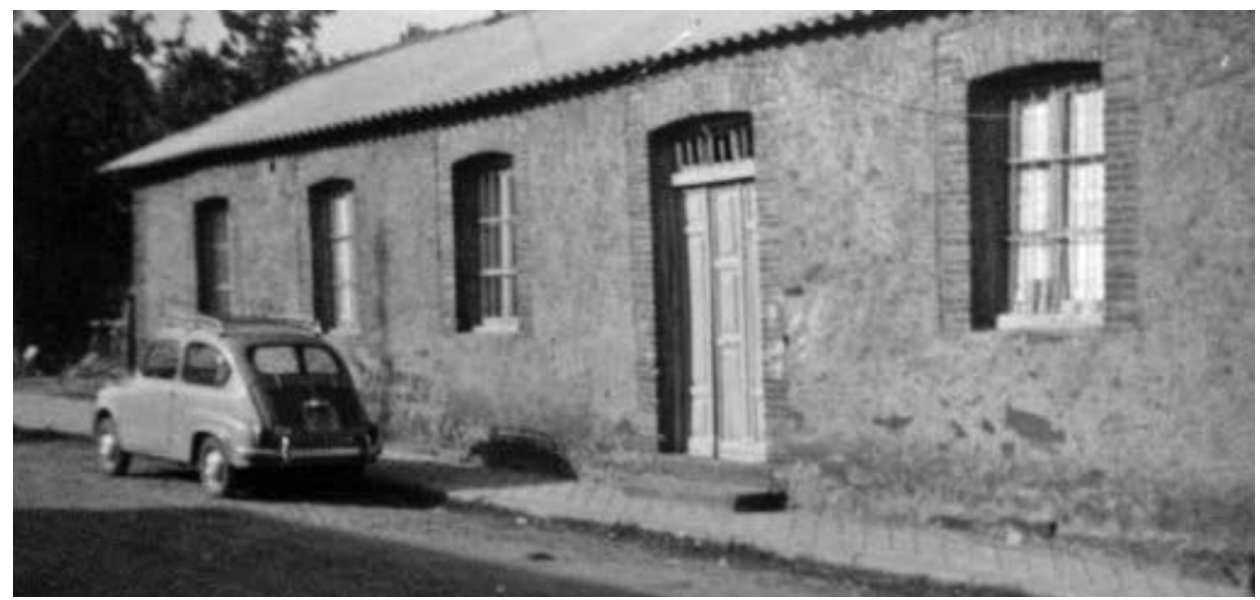

ILUSTRACión 7. Escuela de Villameca. Año de construcción 1928.

Archivo Histórico Provincial de León.

28 Alonso y Garrote, S.: El dialecto vulgar leonés hablado en Maragatería y Tierra de Astorga: notas gramaticales y vocabulario, León, Imprenta Provincial, 1909.

29 Díaz Canseco, L.: «Fuero de San Pedro de las Dueñas (León)», Anuario de Historia del Derecho Español, n. ${ }^{\circ} 2$ (1925), pp. 462-469. 
LOS EDIFICIOS ESCOLARES EN UNA COMARCA LEONESA:

METÁFORAS Y ESTUDIO DE CASO

ISABEL CANTÓN, CRISTINA GONZÁLEZ Y SHEILA HIDALGO

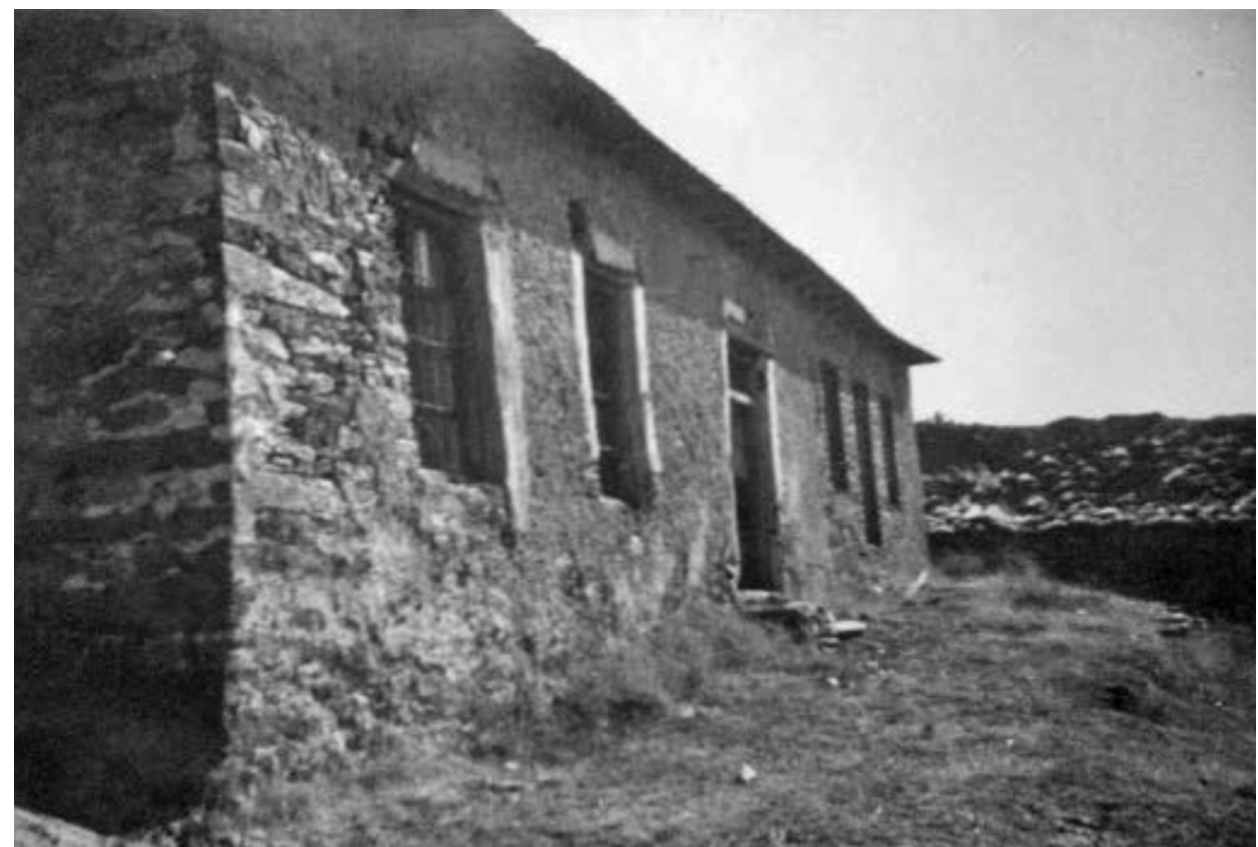

Ilustración 8. Escuela de Villar de los Barrios de Nistoso.

Año de construcción 1930. Archivo Histórico Provincial de León.

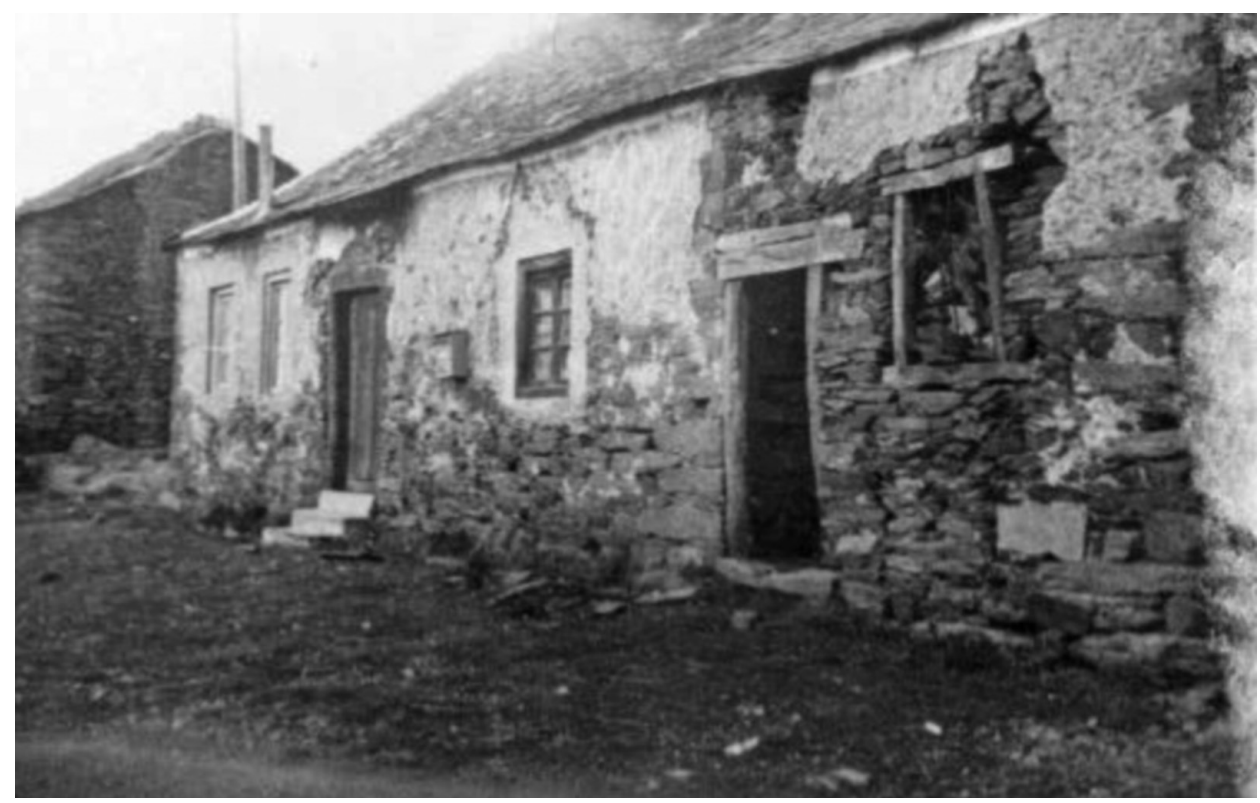

Ilustración 9. Escuela de Tabladas de los Barrios de Nistoso. Año de construcción 1935. Archivo Histórico Provincial de León. 


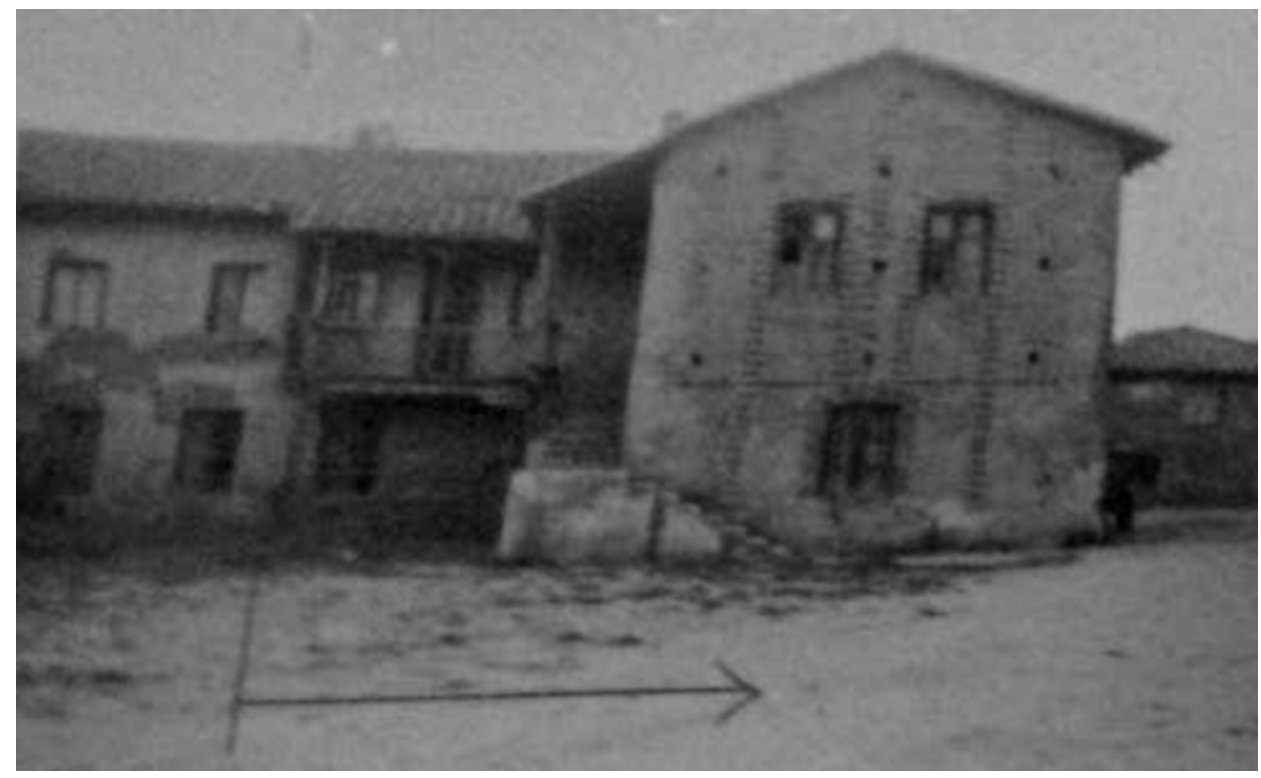

Ilustración io. Escuela de Sueros de Cepeda. Año de construcción i940. Archivo Histórico Provincial de León.

Como se puede apreciar en las imágenes, los edificios escolares fundados en este periodo mantienen unas similitudes entre ellos al tiempo que siguen guardando unas líneas de construcción similares a los edificados en la etapa anterior.

En este periodo, respecto al anterior, se ha observado que la distribución del espacio interior ha evolucionado, pues los edificios escolares, en la mayoría de los casos, pasaron a disponer de dos aulas diferenciadas. Una para los niños y otra para las niñas. Por ello, era habitual que existieran también dos viviendas o espacios destinados a tal uso para los maestros, uno para el maestro y otra para la maestra. Como se puede observar en el plano inferior todos los espacios dentro de la edificación eran independientes, cada uno contaba con su propia puerta de acceso.

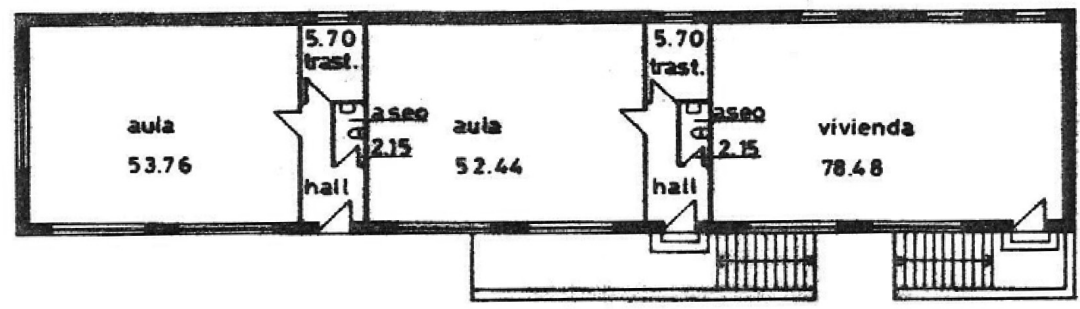

\section{CIRCULACIONES $=10.00 \mathrm{M}^{2}$}

Ilustración ir. Plano del interior de la escuela de Riofrío. Año 1986.

Dirección Provincial de Educación de León. 
Los modelos escolares evolucionan lentamente con la economía de la zona y aparecen ya edificios escolares de planta y piso, aunque el piso era habitualmente la vivienda de los maestros. La construcción escolar es más consistente: aparecen muros de ladrillo en algunos casos, teja árabe en la Cepeda baja y continúa el techado de pizarra en la Cepeda alta. Pasamos del modelo pastoril de la época primera al modelo campesino-agricultor de escuela siguiendo un paralelismo con la evolución diacrónica de la humanidad. Las últimas escuelas de 1950 ya apuntan a modelos más elaborados con introducción de la graduación, separación de edades y sexos, con edificios más acomodados y amplios.

\subsection{Escuelas construidas a partir de ig5o. Escuelas monásticas}

El saber custodiado en los monasterios desde la Edad Antigua y Media dio origen a las escuelas monacales y catedralicias. Estas escuelas se caracterizaban por su intensa labor de lectura, copia y estudio sin distracciones exteriores. Eran todas muy estandarizadas, casi iguales, independientemente del lugar donde se ubicaran, la diferencia estribaba más en la orden religiosa que en el contexto. La aplicación de métodos clásicos de memorización y de rigurosa disciplina bañaba el devenir de estas escuelas donde lo externo era peligroso y malvado. Los edificios de los monasterios eran grandiosos, pero dejaban a la escuela relegada a una parte de la construcción y no daban mucha importancia a las condiciones en que se desarrollaba la enseñanza, meramente instructiva ${ }^{30}$. En el caso de las escuelas cepedanas construidas en esa época, usamos la interpretación y la metáfora para su clasificación y categorización.

La Ley de 22 de diciembre de 1953 reveló el reconocimiento formal de la importancia del problema de construir escuelas. Con ella se otorgó el rango de ley a esta problemática. Además, estableció tres promotores oficiales para esta tarea constructora de escuelas: el Estado, las Juntas Provinciales y los Ayuntamientos, al tiempo que implantó dos sistemas de construcción: el de aportación, por el que las Juntas construían los edificios por sí mismas; y el de subvención, por el que las Juntas ayudaban a construir a los Ayuntamientos. En 1956 con la Ley de I8 de julio le llegó a la de 1953 el respaldo económico que necesitaba para conseguir el modesto objetivo que perseguía, construir mil escuelas. Asimismo, esta última ley dotó a las Juntas Provinciales de personalidad jurídica, dando así un paso decisivo en la descentralización.

En este espacio de tiempo la edificación de escuelas en la comarca de La Cepeda descendió notablemente, pues se construyeron un total de doce escuelas, habiéndose alzado la última en Brimeda en el año 1983. Este descenso se debió probablemente a que la escuela de Sueros de Cepeda y la de Astorga pasaron de ser escuelas graduadas a ser colegios nacionales mixtos y comarcales, lo cual fue consecuencia de que en este periodo se incrementó el flujo migratorio de las

30 Ferzoco, G. y Muessig, C. (eds.): Medieval Monastic Education, New York, Leicester University Press, 2000 . 
zonas rurales a las ciudades. Entre los años cincuenta y setenta se levantaron los edificios escolares de Donillas, Ferreras, Porqueros, Cogorderos, Villamejil, Castrillos de Cepeda, Fontoria de Cepeda, Quintana de Fon, Nistoso y Brañuelas. A partir del año setenta y hasta el año 1983 se edificaron únicamente dos escuelas, ambas eran las segundas que se construían en Corús y en Brimeda.

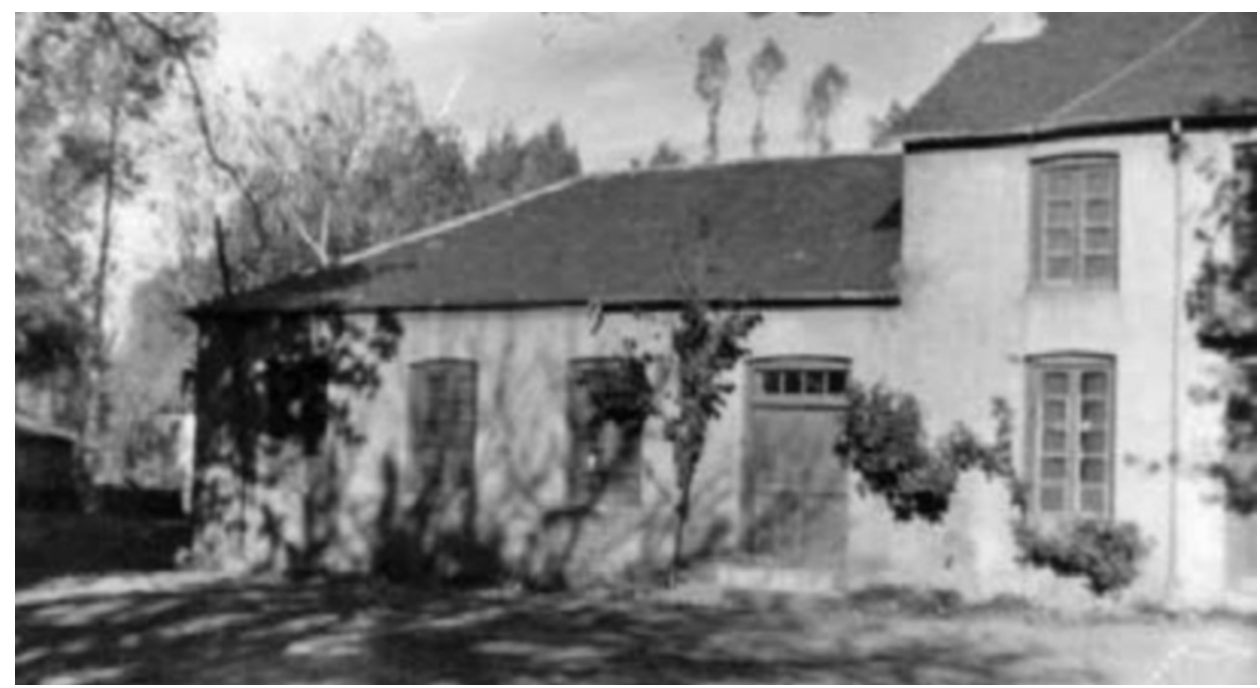

Ilustración I2. Escuela de Donillas. Año de construcción 1952. Archivo Histórico Provincial de León.

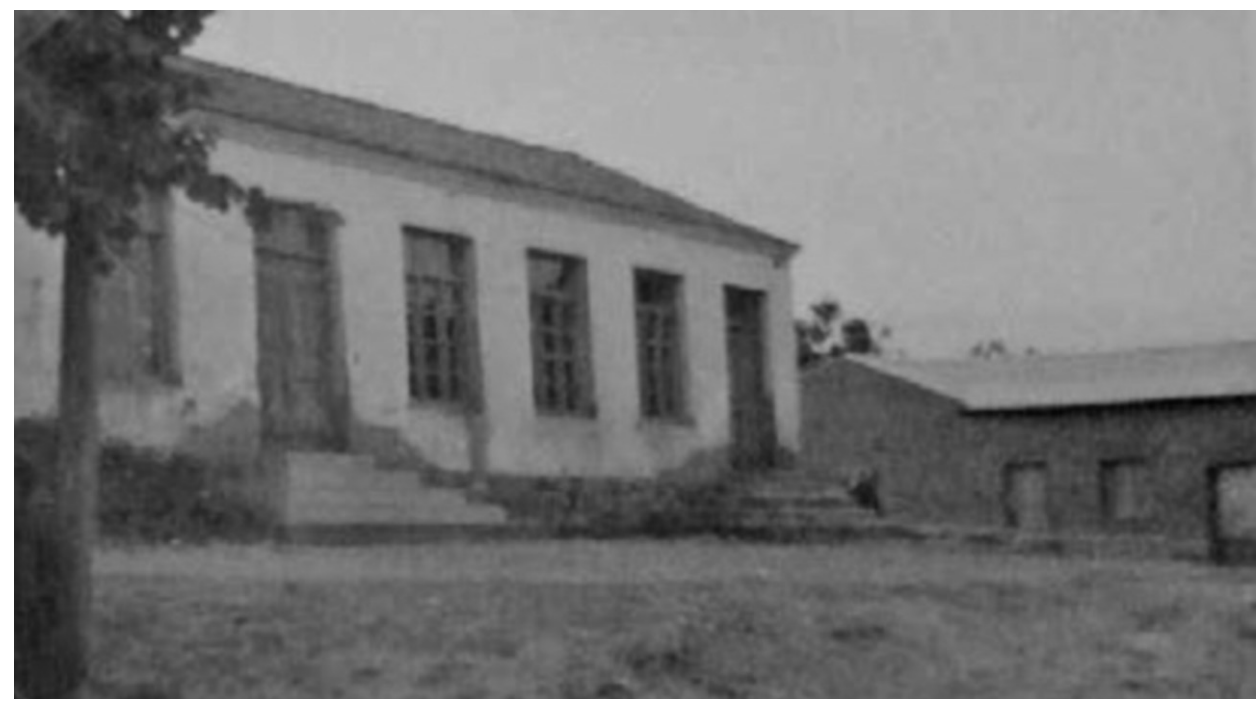

Ilustración i3. Escuela de Ferreras. Año de construcción 1954. Archivo Histórico Provincial de León. 
Estos edificios escolares fueron ampliando su superficie. La mayoría de ellos pasaron a tener dos plantas. Como se puede observar en las imágenes inferiores ya no existe un espacio destinado a vivienda para los maestros. Pasan de tener una o dos aulas a tener varias y a disponer, además, de zonas habilitadas para biblioteca, laboratorios, etcétera.

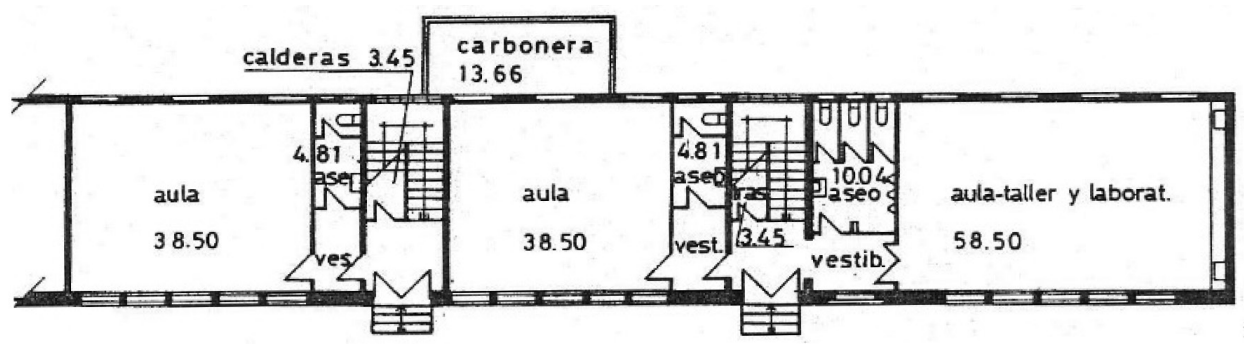

Ilustración i4. Plano de la planta baja de la escuela de Brañuelas. Año 1986. Dirección Provincial de Educación de León.

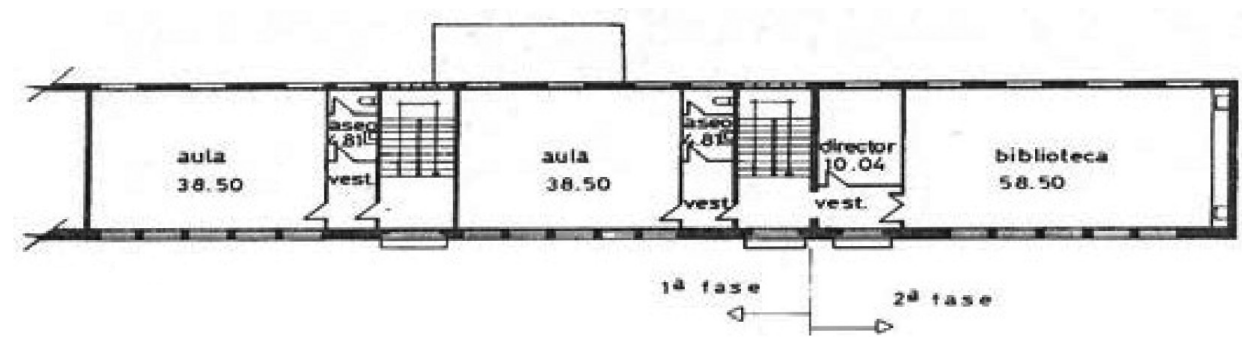

ILustración is. Plano de la primera planta de la escuela de Brañuelas. Año 1986.

Dirección Provincial de Educación de León.

La evolución que se ha ido produciendo en la edificación de escuelas ha sido lenta, sin embargo, según el momento de construcción se aprecian cambios significativos entre los cimentados a finales del siglo xix y los edificados a mediados del siglo xx. La construcción de estos edificios escolares responde, en todos los casos, al intento de cubrir la necesidad existente de escolarizar a los niños y niñas de estos pueblos, sin embargo, en muy pocas ocasiones se logró el objetivo propuesto $^{31}$. El motivo fue casi siempre la escasez de recursos económicos. Además, hay que tener presente que alcanzar la escolarización total no era siempre posible ya que los propios niños, en la mayoría de los casos, tenían que compaginar la tarea de asistir a la escuela con la de cosechar o cuidar el ganado.

La evolución en la distribución de espacios es notoria. De un aula unitaria las escuelas pasaron a ser graduadas y posteriormente colegios mixtos, que en algunos casos eran comarcales. Sin embargo, aunque los materiales hayan ido aumentado en calidad la distribución se ha conservado-el maestro al frente del aula,

${ }^{31}$ Mesmin: ibidem. 
casi siempre subido en un altillo y los alumnos sentados en su pupitre-, esta distribución tenía un objetivo claro: formar alumnos dóciles, pues el maestro, desde esta posición, ejerce, entre otras, una función de vigilancia ${ }^{32}$. Esto ocurre independientemente de la época en la que se haya levantado la escuela. Asimismo, estos edificios escolares están cargados de valores y de toda una semiología que cubre diferentes símbolos estéticos, culturales y aun ideológicos ${ }^{33}$. Esta característica afecta a los edificios escolares que eran especies de monasterios laicos en los que se impartía y transmitía el saber al modo medieval del Trivium y Cuadrivium. La homogeneidad en los edificios construidos en esta época también se enmarca en esa línea de funcionalismo ecléctico ajeno al contexto y a las necesidades de la zona ${ }^{34}$.

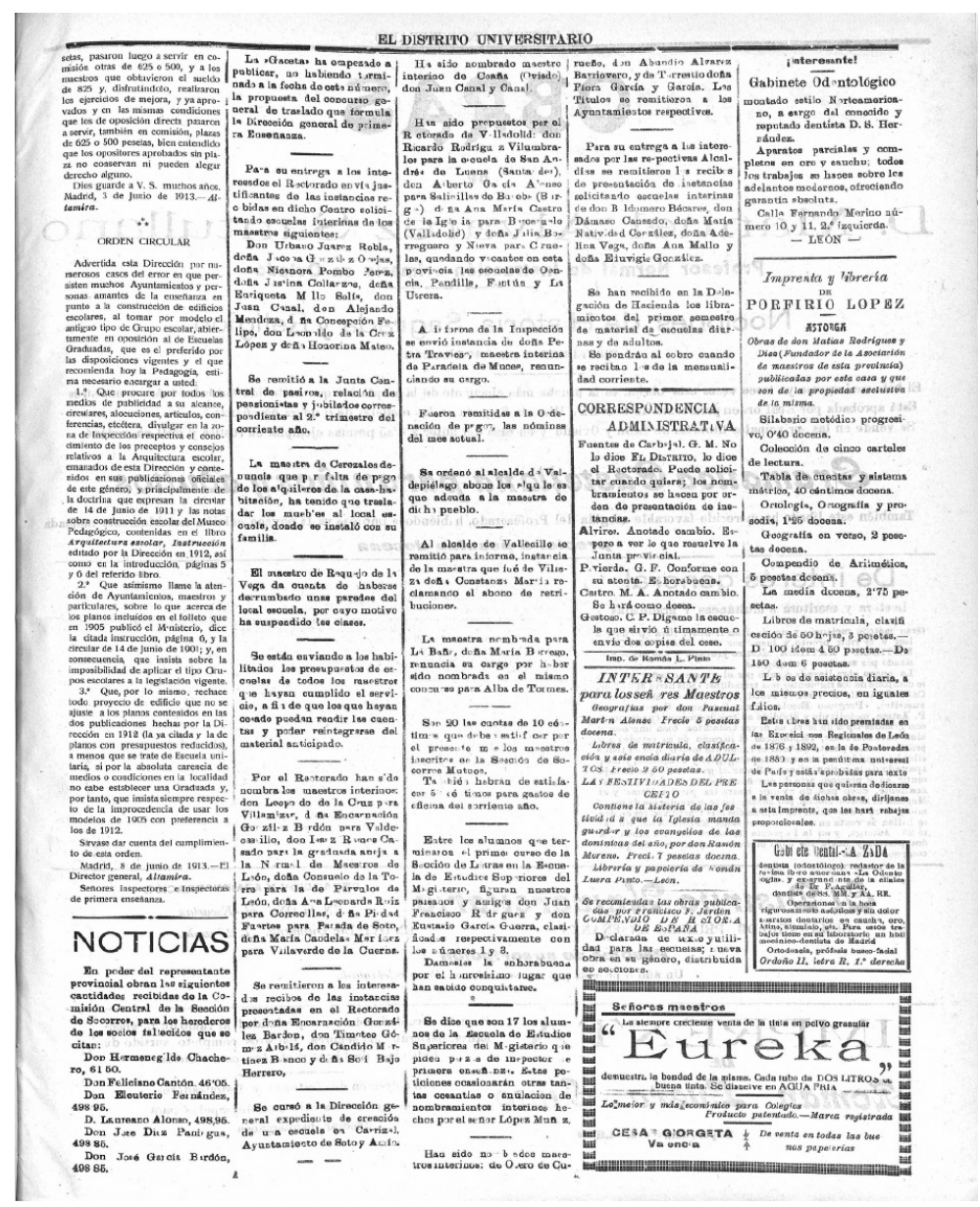

ILUSTRACIÓN i6. Documento de orden de edificaciones escolares.

32 RODRÍGUEZ: 2003, 2006.

33 VIÑAO: ibidem.

34 VIÑAO: ibidem. 


\subsection{Criterio de construcción}

En este criterio valoramos varias cuestiones, por un lado, el tipo de construcción es decir, si se trata de una escuela de planta baja o con varias plantas; por otro lado, tendremos en cuenta la disposición del interior así como la disposición de dependencias; para finalizar hablando de los materiales utilizados para su construcción.

Se sabe que algunas de las escuelas, como la antigua de Vega de Magaz o las escuelas de Benamarías, fueron realizadas por las vecinas y vecinos del pueblo con la ayuda de personas que entendían algo de construcción y de arquitectura: aparejadores, maestros de obra de los pueblos, etcétera. Queremos comentar que hubo momentos que influenciaron de manera notable el tipo de construcciones como, por ejemplo, el paso del Grupo escolar a la Escuela Graduada. Existe una orden circular del Distrito Universitario ${ }^{35}$ del 8 de junio de 1913 en la que se especifica que los preceptos y consejos sobre arquitectura escolar deben ser respetados.

Es importante saber que los espacios escolares están siendo muy estudiados en la actualidad por su vinculación con los tipos de pedagogía y su influencia en el ámbito escolar. Asimismo, existen corrientes actuales sobre la importancia de los materiales y sistemas en la construcción trabajándose, por ejemplo, entre otras disciplinas, la bioconstrucción.

Tal y como dice Viñao Frago ${ }^{36}$ :

La consideración del espacio escolar como un espacio segmentado en el que se distinguen, en primer lugar, las zonas edificadas de las no edificadas y, dentro de ambas, las adscritas a una o a más de una función o tarea de los espacios libres de asignación y abiertos por tanto a posibles adscripciones futuras, plantea, como primera cuestión, la existencia o inexistencia de un espacio específico para una determinada función o tarea. Su inexistencia indicaría, en cada caso, la consideración de dicha tarea como no necesaria o la escasa importancia a ella asignada. Su existencia, a sensu contrario, sería un buen indicador de la relevancia inicial de la misma. Y, junto a ella, serían también buenos indicadores su ubicación, su relación con otros espacios, sus dimensiones y su disposición interna.

No se han construido edificios escolares desde 1986 en La Cepeda, sino que se han reparado o rediseñado para otras funciones los edificios escolares clausurados, por lo que el análisis temporal se detiene aquí.

\section{Conclusiones}

Los edificios escolares tienen corta historia y una trayectoria paralela al desarrollo económico de la zona en la que se insertan. En el caso objeto de nuestro estudio, se mueven entre los años I890 y 1986, menos de un siglo de existencia

35 El Distrito Universitario: Semanario de Ia Enseñanza, León, Año XI, número 589-1913, diciembre I2.

36 Viñao Frago: 2004, p. 28I. 
de edificios escolares en La Cepeda que, sin embargo, configuran su historia, su cultura y su devenir.

La primera etapa de construcción de escuelas en La Cepeda (hasta 1920) la hemos denominado época pastoril, ya que las escuelas edificadas acogían a los niños de forma similar al redil del ganado: aula y patio. No tenían más que la estructura de paredes básicas y techo, mala ventilación y nula calefacción. La similitud de estos edificios con otros anteriores como La Cátedra de Latín de Lois ${ }^{37}$ y su nivel de penuria muestran una tradición de escuela como elemento de segundo orden donde se recogía a los niños como en un aprisco. Ello trascendía y configuraba el tipo de enseñanza que en estos edificios se impartía (Lahoz Abad, I992), que era repetitiva y memorística.

La segunda época, que hemos denominado campesina o agrícola, tiene una evolución hacia estructuras escolares más consistentes ampliando los espacios edificados y apareciendo las casas de maestros, leñeras y aseos. En esa época se deja sentir ligeramente la influencia de la Institución Libre de Enseñanza en la zona que a través de su filial: la Fundación Sierra-Pambley ${ }^{38}$, ya incide en la importancia de la ventilación y la higiene escolar como señala Rodríguez Méndez ${ }^{39}$, con lo que los patios se incrementan y agrandan las ventanas ${ }^{40}$. La enseñanza realmente no sufre grandes cambios ya que se seguía con modelos medievales y memorísticos.

En la tercera época o monástica, la escuela contiene ya estructuras para grupos de alumnos, se complementa con biblioteca, con vestíbulo, aparecen las concentraciones escolares ${ }^{41}$ y con ellas escuelas de planta y piso, edificadas más consistentemente y con arquitectura estandarizada ya lejana a los modelos rurales en los que se insertan. Es la época de la estandarización de la educación al igual que la de los edificios: gran auge de las pruebas de inteligencia, exámenes y libro de calificaciones con la incipiente aplicación de los modelos conductistas. La coincidencia de la arquitectura escolar con la arquitectura domestica rural ${ }^{42}$ es evidente tanto en la estructura de los edificios como en los materiales, formas y parquedad de adornos o elementos que no fueran imprescindibles.

Finalmente, el estudio de la distribución de edificios por Ayuntamientos nos muestra un gran mimetismo de las edificaciones escolares con la vivienda rural de la zona: en La Cepeda alta escuelas construidas en piedra y techadas con pizarra,

37 Cantón Mayo, I. y Prieto Sarro, M.: La cátedra de Latín de Lois, León, Servicio de Publicaciones de la Universidad de León, r999.

38 Cantón Mayo, I.: La Fundación Sierra-Pambley, una institución educativa leonesa, León, Servicio de Publicaciones de la Universidad de León, 1996.

39 Rodríguez Méndez, F. J.: Arquitectura escolar en España: 1857-1936. Madrid como paradigma, tesis doctoral, Madrid, Universidad Politécnica de Madrid, 2004.

$4^{\circ}$ García Salmerón, M. P.: «Mejora e incremento de las construcciones escolares públicas en España», 20I2, en http://tradicióndigital.es/20I2/Io/16.

${ }_{4 \mathrm{I}}$ Morales Romo, N.: La politica de concentraciones escolares en el mundo rural. Repercusiones desde su implantación hasta la actualidad, 20I2. Recuperado de http://escuelarural.net/IMG/ pdf/Politica_concentraciones_escolares.pdf (consultado 08/II/20I2).

${ }^{42}$ Serrano Laso, M.: Arquitectura doméstica en León a principio de siglo (I900-1923), León, Universidad de León y Monteleón, 1992. 


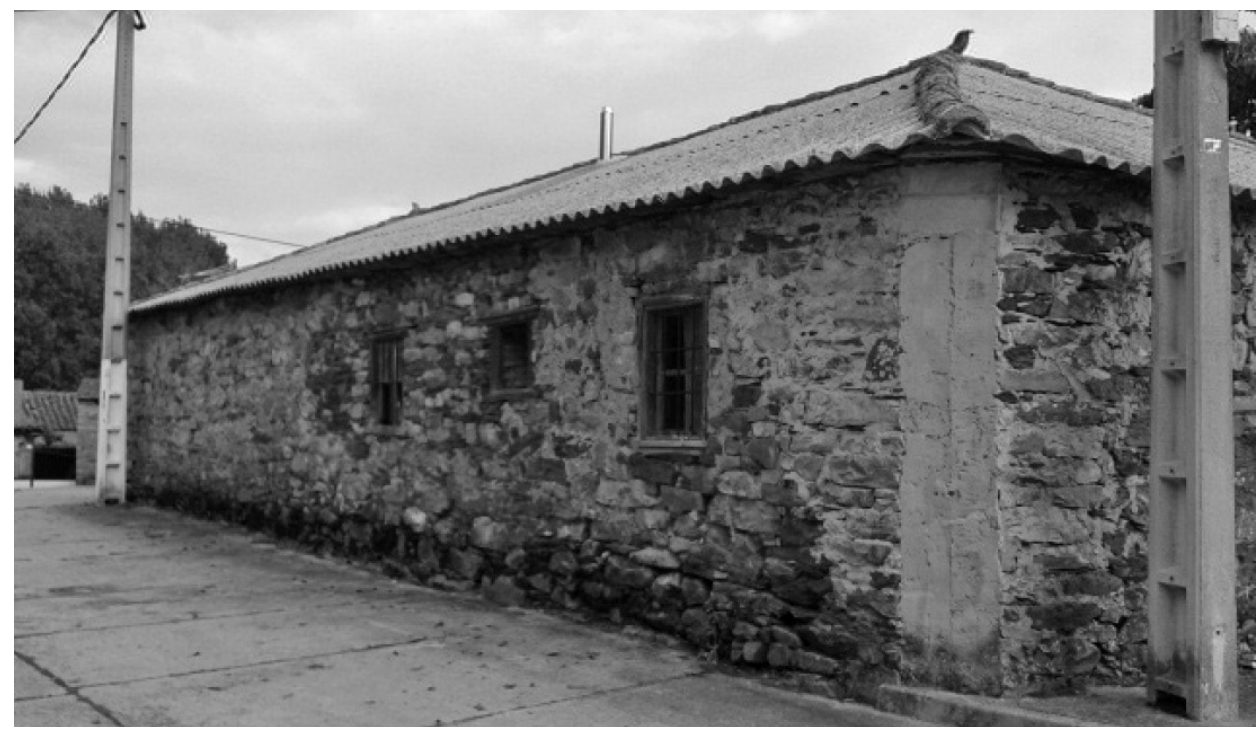

ILUSTRACión I7. Escuela antigua de Villarmeriel. Foto de las autoras.

mientras en La Cepeda baja la construcción es en tapial y la cubierta en teja árabe. Evolutivamente la construcción escolar se ajustaba a la evolución de la vivienda en la zona y va pasando de las primeras construcciones de planta baja a las de planta y piso, como ocurre con Sueros o con Brañuelas.

\section{Discusión}

Los datos del estudio que presentamos aquí son necesariamente incompletos ya que ni en los Archivos Provinciales ni educativos, ni en los pueblos, ni en la Dirección Provincial de Educación hay datos completos seguidos temporalmente que faciliten el seguimiento y evolución de los edificios escolares de La Cepeda. Ello es debido a la discrecionalidad en la forma de llevar su trabajo tanto de los diferentes inspectores, como de la oficina de construcciones escolares. Mientras algunos llevaban un fichero ordenado de los temas que nos ocupan, otros no tenían ninguna documentación al respecto. Es cierto que el trabajo presentado recoge lo existente edificado en la totalidad de los pueblos de la comarca cepedana y no llega a la exhaustividad deseada, pero parte de una premisa de inexistencia y ello siempre es un paso adelante. La metodología mixta etnográfica y descriptivo-explicativa e interpretativa utilizada, dentro de la línea cualitativa, ha permitido recuperar y poner en valor los edificios escolares de 46 localidades y cinco Ayuntamientos. Una arqueología de la arquitectura escolar podría reconstruir los edificios en su forma primitiva y ampliar la interpretación de los mismos. En todo caso lo que se presenta y analiza en este artículo supone un gran avance 
en la recuperación del patrimonio material e inmaterial de la escuela que está en grave peligro de desaparición.

\section{Bibliografía}

Alonso y Garrote, S.: El dialecto vulgar leonés hablado en Maragatería y Tierra de Astorga: notas gramaticales y vocabulario, León, Imprenta Provincial, I909.

Bello, L.: «Llegada a León. La provincia modelo», en Bello, L.: Viaje por las Escuelas de España, Madrid, Magisterio Español, 1926.

Bello, L.: Viaje por las escuelas de Castilla y León, edición y estudio introductorio de Agustín Escolano, Ámbito, Valladolid, 1995.

Burke, C.: «Introduction. Containing the school child: architectures and pedagogies», Paedagogica Historica, 4I (4-5), (2005), pp. 489-494.

Cantón Mayo, I.: La Fundación Sierra-Pambley, una institución educativa leonesa, León, Servicio de Publicaciones de la Universidad de León, 1996.

Cantón Mayo, I. y Prieto Sarro, M.: La cátedra de Latín de Lois, León, Universidad de León, I999.

Carreras, A. y Tafunell, X.: Estadísticas históricas de España, Madrid, fundación Bbva, 2005.

Corchón Álvarez, E.: La escuela rural: pasado, presente y perspectivas de futuro, Barcelona, Oikos-Tau, 2000.

Corchón, E.: La escuela en el medio rural: modelos organizativos, Barcelona, Davinci Continental, 2005.

Díaz Canseco, L.: «Fuero de San Pedro de las Dueñas (León)», Anuario de Historia del Derecho Español, n. ${ }^{\circ} 2$ (1925), pp. $462-469$.

Escolano Benito, A.: «Introducción», en Escolano Benito, A. y cols.: Historia ilustrada de la escuela de España: Dos siglos de perspectiva histórica, Madrid, Fundación Germán Sanchez Ruipérez, pp. I3-I4.

FernÁndez GutiérRez, M. F.: «El contexto del proyecto arquitectónico: la renovación de la construcción escolar en España (1920-1936)», Boletín de Letras del Real Instituto de Estudios Asturianos (BIDEA), Oviedo, n. ${ }^{\circ}$ I57 (enero-junio, 200I), pp. I77-245.

Ferzoco, G. y Muessig, C. (eds.): Medieval Monastic Education, New York, Leicester University Press, 2000.

García Álvarez, A.: La Cepeda a finales del Siglo XX, 2009, en http://www.saber.es/web/ biblioteca/libros/tierras-de-leon/html/65/2cepeda.pdf.

García Salmerón, M. P.: «Mejora e incremento de las construcciones escolares públicas en España», 20I2, en http://tradicióndigital.es/20I2/Io/I6.

Giner de los Ríos, B.: Las construcciones escolares de Madrid. Oficina Técnica para la construcción de escuelas, Madrid, Ministerio de Instrucción Pública y Bellas Artes, 1933.

Hammersley, M. y Atrinson, P.: Etnografía. Métodos de investigación, Barcelona, Paidós, I994.

Hernández Díaz, J. M.: La Escuela Primaria en Castilla y León: Estudios Históricos, Valladolid, Ámbito, 1993.

Hernández Díaz, J. M.: «La escuela rural en la España del siglo xx», Revista de Educación, número extraordinario (2000), pp. II3-136.

Jiménez SÁnchez, J.: La escuela unitaria, Barcelona, Laia, 1983.

LAHOz AbAD, P.: «Higiene y arquitectura escolar en la España contemporánea (I836-1936)», Revista de Educación, 298 (1992), pp. 89-II8.

Lahoz Abad, P.: «Los modelos escolares de la Oficina Técnica para Construcción de Escuelas», Historia de la Educación, I2-I3 (1993-I994), pp. I2I-I48. 
LÁzaro Flores, E.: «Historia de las construcciones escolares en España», Revista de Educación, n. 240 (1975), pp. II4-I26.

Ley de Instrucción Pública de 9 de septiembre de 1857 (Ley Moyano I857).

Madoz, P.: Diccionario geográfico-estadístico-historico de España y sus posesiones de ultramar, I886-1870, Junta de Castilla y León. Facsímil en 2012-13.

Mesmin, G.: L'enfant, l'architecture et l'espace, Tournai, Casterman, 1973.

Mingote y Tarazona, P.: Guía del viajero en León y su provincia, León, Establecimiento Tipográfico de Miñón, i879.

Morales Romo, N.: La politica de concentraciones escolares en el mundo rural. Repercusiones desde su implantación hasta la actualidad, 20I2, recuperado de http://escuelarural.net/ IMG/pdf/Politica_concentraciones_escolares.pdf (consultado 08/II/2OI2).

Rodríguez Méndez, J.: «Renouvellement architectural et pédagogie du plein air en Espagne (1910-1936)», en Châtelet, A.-M.; Lerch, D. y Luc, J.-N. (dirs.): L'école en plein air. Une experience pédagogique et architectural dans l'Europe $d u X X^{e}$ siècle, Paris, Éditions Recherches, 2003, pp. 148-167.

Rodríguez Méndez, F. J.: Arquitectura escolar en España: 1857-1936, Madrid como paradigma, tesis doctoral, Madrid, Universidad Politécnica de Madrid, 2004.

Rodríguez Méndez, J.: «La Institución Libre de Enseñanza y la arquitectura escolar», Historia de la Educación, 25 (2006), pp. 467-491.

Samaniego Boneu, M.: La política educativa de la segunda República durante el bienio Azanista, Madrid, CSIC, 1977.

Schokel, L. A. y Bravo, J. M.: Apuntes de hermenéutica, Madrid, Editorial Trotta, 1994.

Serrano Laso, M.: Arquitectura doméstica en León a principio de siglo (1900-1923), León, Universidad de León y Monteleón, 1992.

Torres Balbás, L.: «Los edificios escolares vistos desde la España rural», en Exposición de arquitectura escolar, $\mathrm{I} 3,20$ y 27 de febrero de 1933.

unEsco: Definición elaborada por la Conferencia Mundial de la unesco sobre el Patrimonio Cultural, celebrada en México en el año i982.

Vilanova, M. y Moreno, X.: Atlas de la evolución del analfabetismo en España de I887 a I98I, Ministerio de Educación, CIDE, I992, vol. 72.

VIÑAO, A.: «Escolarización, edificios y espacios escolares», CEE Participación Educativa (marzo, 2008), pp. 16-27.

\section{Anexo I}

\section{Clasificación metafórica de las Escuelas Cepedanas}

Escuelas Pastoriles. Todas las escuelas proceden de fotos antiguas del Archivo Histórico Provincial de León. La calidad es siempre mala, pero es lo que hay.

I. Escuela de La Silva.

2. Escuela de Montealegre.

3. Escuela de Manzanal del puerto.

4. Escuela de Brimeda.

5. Escuela de Carneros.

6. Escuela de Castro de Cepeda.

7. Escuela de Vanidodes. 
8. Escuela de Requejo.

9. Escuela de Escuredo.

ı. Escuela de Palaciosmil.

Escuelas Campesinas

II. Escuela de Quintana del Castillo.

I2. Escuela de Villameca.

I3. Escuela de Tabladas.

I4. Escuela de Villar.

I5. Escuela de Corús.

I6. Escuela de Culebros.

17. Escuela de Villaobispo de Otero.

I8. Escuela de Benamarías.

19. Escuela de Magaz de Cepeda.

20. Escuela de Vega de Magaz.

2I. Escuela de Zacos.

22. Escuela de Morriondo.

23. Escuela de San Feliz de las Lavanderas.

24. Escuela de Ucedo.

25. Escuela de Valbuena de la Encomineda.

26. Escuela de Villagatón.

27. Escuela de Castrillo de Cepeda.

28. Escuela de Revilla.

29. Escuela de Sueros de Cepeda.

30. Escuela de Sopeña de Carneros.

3I. Escuela de Abano.

32. Escuela de Riofrío.

Escuelas Monásticas

33. Escuela de Donillas.

34. Escuela de Ferreras.

35. Escuela de Porqueros.

36. Escuela de Cogorderos.

37. Escuela de Villamejil.

38. Escuela de Castrillo de Cepeda.

39. Escuela de Fontoria de Cepeda.

40. Escuela de Quintana de Fon.

4I. Escuela de Nistoso.

42. Escuela de Brañuelas. 